\title{
The collateral impact of COVID19 among surgeons and residents: Second cross-sectional survey about the Colombian perspective
}

\author{
El impacto colateral del COVID-19 entre cirujanos y residentes: \\ Segunda encuesta transversal sobre la perspectiva colombiana
}

\author{
Carlos E. Díaz-Castrillón' $\mathbb{D}$, Natalia Cortés ${ }^{2} \mathbb{D}$, Juan F. Díaz-Castrillón ${ }^{3}$, Manuela Pineda4, \\ Sara Sierra ${ }^{5}$
}

\begin{abstract}
Research fellow, Department of Cardiothoracic surgery, University of Pittsburgh Medical Center, Pittsburgh, United States of America. Médica, especialista en Cirugía general, Departamento de Cirugía, Pontificia Universidad Javeriana, Bogotá, D.C., Colombia. Médico, Clínica del Country, Bogotá, D.C., Colombia.

Médico, residente de Cirugía general, Pontificia Universidad Javeriana, Bogotá, D.C., Colombia.

Research fellow, Department of surgery, University of Illinois, Chicago, United States of America.
\end{abstract}

\begin{abstract}
Introduction. The COVID-19 pandemic has led health services to adapt, surgical training has had to restructure, and personal life has had to thrive hardships. We aimed to describe the evolution of surgeons' and residents' perceptions about the impact COVID-19 has had on Colombia's surgical practice.
\end{abstract}

Methods. Descriptive cross-sectional study using a structured electronic survey among general surgery residents, and graduated surgeons who have a clinical practice in Colombia.

Results. 355 participants were included, with a median age of 37 years (IQR 30, 51), and 32.1\% female. There were $28.7 \%$ residents, $43.3 \%$ general surgeons, and $27.8 \%$ subespecialist in surgery. Overall, $48.7 \%$ of respondents were from Bogotá, and 38.8\% worked at academic private hospitals. Although almost all participants reported having used telemedicine platforms during the pandemic, $58 \%$ of the respondents did not view telemedicine as sufficient for follow-up consults. More than $80 \%$ of surgeons surveyed reported that their monthly incomes had been reduced.

Discussion. The second survey showed a better-perceived adherence to safety protocols at their institutions than at the beginning of the pandemic. However, the toll on economic and academic domains are substantial among the surgical community. As the pandemic's effects are expected to last longer in our region, telemedicine services acceptance and healthcare providers' job stability need to be improved in Colombia.

Keywords: COVID-19; coronavirus infections; pandemics; perception; surveys and questionnaires; general surgery; health postgraduate programs; Colombia.

Fecha de recibido: 26/01/2021 - Fecha de aceptación: 09/02/2021 - Fecha de publicación en línea: 05/03/2021 Correspondencia: Carlos Eduardo Díaz-Castrillón, M.D. Faculty Pavilion-Fifth Floor, 4401 Penn Avenue, Pittsburgh, PA 15224.

Telefono: (+1) 412-580-3204. E-mail: diazcastrillonce@upmc.edu

Citar como: Díaz-Castrillón CE, Cortés N, Díaz-Castrillón JF, Pineda M, Sierra S. The collateral impact of COVID19 among surgeons and residents: Second cross-sectional survey about the Colombian perspective. Rev Colomb Cir. 2021;36:312-23.

https://doi.org/10.30944/20117582.877

Este es un artículo de acceso abierto bajo una Licencia Creative Commons - BY-NC-ND https://creativecommons.org/licenses/by-ncnd/4.0/deed.es 


\section{Resumen}

Introducción. La pandemia ha llevado a los servicios de salud a adaptarse, la formación quirúrgica ha tenido que reestructurarse y la vida personal ha tenido que prosperar en las dificultades. Nuestro objetivo fue describir la evolución de las percepciones de cirujanos y médicos residentes sobre el impacto que ha tenido el CoVID-19 en la práctica quirúrgica de Colombia.

Métodos. Estudio de corte transversal descriptivo mediante encuesta estructurada distribuida electrónicamente a médicos residentes de cirugía general, cirujanos generales o sub-especialistas, con práctica clínica en Colombia.

Resultados. Se incluyeron 355 participantes, con una mediana de edad de 37 años (RIC 30-51) y el 32,1 \% fueron mujeres. El 28,7 \% eran médicos residentes, el 43,3 \% cirujanos generales y el 27,8 \% subespecialistas en cirugía. El 48,7 \% de los encuestados vivían en Bogotá y el 38,8 \% trabajaba en hospitales académicos privados. Aunque la mayoría ha utilizado plataformas de telemedicina durante la pandemia, el 58 \% de los encuestados no consideró que la telemedicina fuera suficiente para las consultas postoperatorias. Más del $80 \%$ de los cirujanos encuestados informaron que sus ingresos mensuales se habían reducido.

Discusión. La segunda encuesta mostró una mejor percepción de la adherencia a los protocolos de seguridad en sus instituciones que al comienzo de la pandemia. Sin embargo, el costo en los dominios económicos y académicos es considerable entre la comunidad quirúrgica. Dado que se espera que los efectos de la pandemia duren más en nuestra región, es necesario mejorar la aceptación de los servicios de telemedicina y la estabilidad laboral de los proveedores de atención médica en Colombia.

Palabras clave: COVID-19; infecciones por coronavirus; pandemias; percepción; encuestas y cuestionarios; cirugía general; programas de postgrado; Colombia.

\section{Introduction}

After declaring a pandemic in 2020, national and global public health agencies started to elucidate the best way to respond to this unusual challenge. From the public health perspective, social distancing and massive testing strategies were adopted broadly around the world; as health-care organizations focused their efforts on providing training on new protocols to medical staff, securing a stock of personal protective equipment (PPE), and creating additional facilities to match the increased demand for intensive care units (ICU) ${ }^{1,2}$.

Although countries tried to follow the same response pathway, the situation in Latin America was different since most of Latin American countries' healthcare systems had already a limited response capacity. According to the United Nations Economic Commission for Latin America (CEPAL), 16 Latin American countries invested less than $4 \%$ of their GDP to healthcare in $2018^{3}$.
Furthermore, with a density of surgical, anesthetic and obstetric providers of 13.7 per 100.000 population in Colombia ${ }^{4}$, we lagged behind the Lancet Commission on Global Surgery recommended target of 20 per 100.000 population ${ }^{5}$.

As a consequence, prolonged city lockdowns were instituted and early cancellation of non-essential elective surgery by health organizations was adopted, aiming at preparing the health system in Colombia ${ }^{6}$. However, with the America continent at the epicenter of the pandemic, the impact on surgical services has been extensive in our region ${ }^{7}$. Given the sparse data regarding the consequences of the pandemic in our country and the results from the first survey at the beginning of the pandemic ${ }^{8}$, we aim to describe the evolution of the perceptions from surgeons and residents about the impact COVID-19 have had on their surgical practice, as well as to explore how training and life have been modified during the peak of the pandemic in Colombia. 


\section{Methods}

\section{Study design and participants}

In this cross-sectional study, an online-based, anonymous, structured voluntary survey was ${ }^{1}$ distributed via email from the mailing list of the Colombian Association of Surgery (ASCOL, in its Spanish acronym); ${ }^{2}$ made publicly available through Twitter and Facebook platforms; and ${ }^{3}$ sent via Whatsapp text messages with a link to the questionnaire. Only a single response to the questionnaire was permitted for each participant and the study population targeted were general surgeons or general surgery subspecialists practicing in Colombia as well as general surgery residents from academic programs in Colombia. As per direct communication with ASCOL, there are currently 20 general surgery residency programs and 320 residents in Colombia. Furthermore, Hanna et al estimated there were 2,475 surgery especialists for a density of 5 surgeons per 100,000 population as in $2018^{4}$.

\section{Questionarie}

The domains evaluated were developed through a modified Delphi method and included an infection risk perception, surgical practice impact, and personal impact domains. The questionnaire included multiple selection and Likert-item questions on basic demographic data, occupational exposure experience, risk perception of COVID-19 and the impact of COVID-19 on lifestyle, economic and education aspects. The survey was available at the public domain surveyplanet.com (C) 2020 Survey Planet, LLC) from July 22, 2020 to August 6, 2020.

\section{Statistical analysis}

Survey results were imported and analysed using Stata 15 (StataCorp LP, College Station, TX, USA). Data is described as proportions (\%) for categorical variables and as medians with interquartile range (IQR) for continuous variables. We used the non-parametric Pearson Chi square test, Fisher exact test and the Kruskall-Wallis test whenever appropiate.

\section{Results}

A total of 355 participants were included, with a median age of 37 years (IQR 30,51), and $32.1 \%(n=114)$ female. The biggest proportion of the population $(48.7 \%, n=173)$ reported to work in Bogota, followed by Medellin (9.8\%, $\mathrm{n}=35)$ and Cali $(8.7 \%, \mathrm{n}=31)$ (Table 1). There were $28.7 \%(n=102)$ general surgery residents,

Table 1. Demographic characteristics.

\begin{tabular}{lc}
\hline Variables & $\mathbf{n}=\mathbf{3 5 5}$ \\
\hline Age, median (IQR) & $37(30,51)$ \\
Female, n (\%) & $114(32.1)$ \\
Training level & $\mathbf{n}(\%)$ \\
General surgeon & $154(43.4)$ \\
Subespecialist surgeon & $99(27.9)$ \\
Resident & $102(28.7)$ \\
Type of Hospital & $\mathbf{n}(\%)$ \\
Private Universitary & $138(38.9)$ \\
Public Universitary & $88(24.8)$ \\
Private Non-Universitary & $101(28.4)$ \\
Public Non-Universitary & $28(7.9)$ \\
City & $\mathbf{n}(\%)$ \\
Bogotá / Sabana de Bogotá & $173(48.7)$ \\
Medellin & $35(9.8)$ \\
Cali & $31(8.7)$ \\
Barranquilla & $22(6.2)$ \\
Cartagena & $13(3.7)$ \\
Bucaramanga & $10(2.8 \%)$ \\
Neiva & $9(2.5)$ \\
Popayán & $7(2)$ \\
Montería & $6(1.7)$ \\
Villavicencio & $6(1.7)$ \\
Pereira & $5(1.4)$ \\
Manizales & $4(0.9)$ \\
Santa Marta & $3(0.9)$ \\
Tunja & $2(0.5)$ \\
Garzon & $2(0.5)$ \\
Oalledupar & $2(0.5)$ \\
Citers & $2(0.5)$ \\
Puta & $17(4.7)$ \\
\hline
\end{tabular}

* Cities with 1 participant: Buenaventura, Espinal, Florencia, Girardot, Honda, Ibague, Manangue, Pamplona, Rionegro, Sahagun, San Andres, Sincelejo, Socorro, Tumaco, Ubate, Yarumal, Yopal. 
$43.3 \%(n=154)$ general surgeons, and $27.8 \%$ ( $\mathrm{n}=99$ ) subspecialist surgeons, accounting for a $31.8 \%$ and $10.2 \%$ response rate among residents and surgeons. Most of the participants worked at an academic private hospital (38.8\%, $\mathrm{n}=138$ ), followed by non-academic private hospital $(28.4 \%, \mathrm{n}=102)$, academic public hospital $(24.7 \%, \mathrm{n}=88)$, and non-academic public hospital $(7.8 \%, \mathrm{n}=28)$. Among graduated surgeons, $65.6 \%(n=166)$ of the participants reported to work in more than 1 hospital.

\section{Perception of COVID19 Infection Domain}

A total of $56.6 \%(n=206)$ participants endorsed that the recommended safety protocols have been fulfilled completely at their institutions, followed by $40 \%(n=140)$ who stated that protocols have been partially followed (Table 2). In terms of PPE, the $\mathrm{N} 95$ mask was the most frequently missing element reported by $51.8 \%(n=184)$ participants, followed by disposable gowns reported by $16 \%$ $(\mathrm{n}=57)$ (Figure 1).

Overall, 72.9\% ( $n=259)$ participants reported to have had direct contact with COVID-19 positive patients, with a reported infection rate of $6.5 \%$ $(n=23)$ among respondents (Figure 2). Although a higher proportion of residents have been in direct contact with COVID-19 positive patients, no differences were observed in reported COVID-19 infections among respondents (Table 2). In general, $57.4 \%(n=204)$ participants felt safe during surgical procedures at the moment the survey was answered, in contrast to $29 \%(n=103)$ who did not.

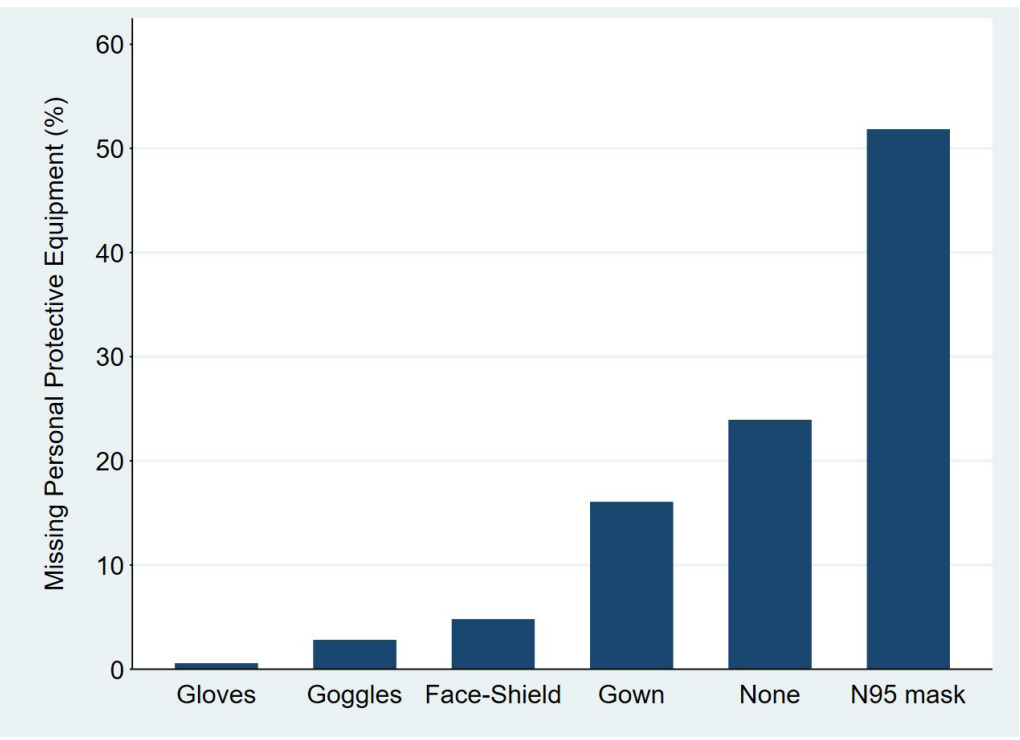

Figure 1. Reported most frequent missing protective personal equipment.

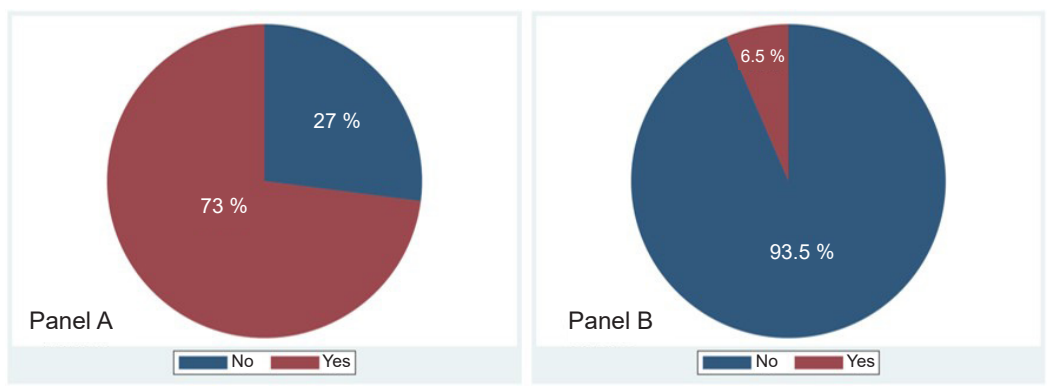

Figure 2. Self-reported notion of direct contact (Panel A) and infection (Panel B) with COVID-19 among participants. 
Table 2. Perception evolution about COVID-19 safety protocols and risk of infection.

\begin{tabular}{|c|c|c|c|c|c|}
\hline Question & Total $(n=355)$ & $\begin{array}{l}\text { General surgeon } \\
\quad(n=154)\end{array}$ & $\begin{array}{l}\text { Subspecialist } \\
\text { surgeon } \\
(n=99)\end{array}$ & $\begin{array}{l}\text { Resident } \\
(n=102)\end{array}$ & $p$ value \\
\hline $\begin{array}{l}\text { Compared to the lockdown phase, Do } \\
\text { you considered that the recommended } \\
\text { safety protocols are currently being } \\
\text { followed? }\end{array}$ & & & & & 0.02 \\
\hline Completely & $201(56.6 \%)$ & $86(55.8 \%)$ & $67(67.7 \%)$ & $48(47.1 \%)$ & \\
\hline Partially & $142(40.0 \%)$ & $64(41.6 \%)$ & $27(27.3 \%)$ & $51(50.0 \%)$ & \\
\hline Not being followed & $5(1.4 \%)$ & $3(1.9 \%)$ & $1(1.0 \%)$ & $1(1.0 \%)$ & \\
\hline Unknown & $7(2.0 \%)$ & $1(0.6 \%)$ & $4(4.0 \%)$ & $2(2.0 \%)$ & \\
\hline $\begin{array}{l}\text { Compared to the lockdown phase, } \\
\text { Do you currently feel safe operating } \\
\text { on patients COVID-19 positive? }\end{array}$ & & & & & 0.59 \\
\hline Strongly agree or Agree & $204(57.5 \%)$ & $88(57.1 \%)$ & $54(54.5 \%)$ & $62(60.8 \%)$ & \\
\hline Undecided & $48(13.5 \%)$ & $17(11.0 \%)$ & $16(16.2 \%)$ & $15(14.7 \%)$ & \\
\hline Strongly disagree or Disagree & $103(29.0 \%)$ & $49(31.8 \%)$ & $29(29.3 \%)$ & $25(24.5 \%)$ & \\
\hline $\begin{array}{l}\text { Have you had direct contact with } \\
\text { a positive COVID-19 patient: }\end{array}$ & & & & & 0.007 \\
\hline Yes & $259(73.0 \%)$ & $108(70.1 \%)$ & $65(65.7 \%)$ & $86(84.3 \%)$ & \\
\hline No & $96(27.0 \%)$ & $46(29.9 \%)$ & $34(34.3 \%)$ & $16(15.7 \%)$ & \\
\hline $\begin{array}{l}\text { Have you been diagnosed with } \\
\text { COVID-19 infection? }\end{array}$ & & & & & 0.23 \\
\hline Yes & $23(6.5 \%)$ & $9(5.8 \%)$ & $4(4.0 \%)$ & $10(9.8 \%)$ & \\
\hline No & $332(93.5 \%)$ & $145(94.2 \%)$ & $95(96.0 \%)$ & $92(90.2 \%)$ & \\
\hline $\begin{array}{l}\text { Compared to the lockdown phase, } \\
\text { Do you consider that the postoperative } \\
\text { complications secondary to COVID-19 } \\
\text { infection have increased? }\end{array}$ & & & & & 0.01 \\
\hline Strongly agree or Agree & $154(43.3 \%)$ & $61(39.6 \%)$ & $37(37.4 \%)$ & $56(54.9 \%)$ & \\
\hline Undecided & $106(29.8 \%)$ & $46(29.9 \%)$ & $29(29.3 \%)$ & $31(30.4 \%)$ & \\
\hline Strongly disagree or Disagree & $95(26.7 \%)$ & $47(30.5 \%)$ & $33(33.3 \%)$ & $15(14.7 \%)$ & \\
\hline
\end{tabular}

\section{Perception about Impact on Professional Life}

In general, $69.5 \%(n=247)$ of the participants reported that non-essential elective surgery was still being performed at their institutions, with no differences observed between academic and non-academic hospitals (68.6\% vs. $71.3 \%$; $\mathrm{p}=0.5)$. Furthermore, $43.3 \%(\mathrm{n}=154)$ of respondent affirmed that postoperative complications secondary to COVID-19 infection have increased during lockdown phase, without differences by the type of hospital ( $43.1 \%$ vs. $44.0 \%$; $\mathrm{p}=0.97$ ).

A total of $73.0 \%(n=259)$ of the participants considered that complications secondary to de- layed presentation have increased in contrast to the beginning of the pandemic in Colombia, again with no difference between academic and non-academic hospitals (73.6\% vs. $71.6 \%$; $\mathrm{p}=0.96)$. Nevertheless, $43.7 \%(n=155)$ and $42.3 \%(n=150)$ of the participants perceived that trauma-related and inflammatory pathology-related admissions have not increased related to the lockdown phase (Table 3).

Lastly, $54.9 \%(n=195)$ of the participats stated to have used telemedicine services with their patients, being significantly higher for subspecialist compared to general surgeons $(78.8 \%$ vs. $48.7 \%$ vs. $41.2 \%$; $\mathrm{p}<0.001)$. However, $58.1 \%(\mathrm{n}=206)$ 
Table 3. Perception about surgical services.

\begin{tabular}{|c|c|c|c|c|c|}
\hline Question & $\begin{array}{c}\text { Total } \\
(n=355)\end{array}$ & $\begin{array}{l}\text { General surgeon } \\
\quad(n=154)\end{array}$ & $\begin{array}{c}\text { Subspecialist } \\
\text { surgeon } \\
(n=99)\end{array}$ & $\begin{array}{c}\text { Resident } \\
(n=102)\end{array}$ & $p$ value \\
\hline $\begin{array}{l}\text { Compared to the lockdown phase, } \\
\text { Do you consider that complications } \\
\text { secondary to delayed emergency } \\
\text { room consultation have increased? }\end{array}$ & & & & & 0.01 \\
\hline Strongly agree or Agree & $259(73.0 \%)$ & $119(77.3 \%)$ & $60(60.6 \%)$ & $80(78.4 \%)$ & \\
\hline Undecided & $50(14.1 \%)$ & $15(9.7 \%)$ & $24(24.2 \%)$ & $11(10.8 \%)$ & \\
\hline Strongly disagree or Disagree & $46(13.0 \%)$ & $20(13.0 \%)$ & $15(15.2 \%)$ & $11(10.8 \%)$ & \\
\hline $\begin{array}{l}\text { Compared to the lockdown phase, } \\
\text { Do you consider that trauma-related } \\
\text { admissions have increased: }\end{array}$ & & & & & $<0.001$ \\
\hline$>75 \%$ & $6(1.7 \%)$ & $2(1.3 \%)$ & $2(2.0 \%)$ & $2(2.0 \%)$ & \\
\hline $50-75 \%$ & $26(7.3 \%)$ & $12(7.8 \%)$ & $3(3.0 \%)$ & $11(10.8 \%)$ & \\
\hline $25-51 \%$ & $52(14.6 \%)$ & $24(15.6 \%)$ & $9(9.1 \%)$ & $19(18.6 \%)$ & \\
\hline$<25 \%$ & $49(13.8 \%)$ & $23(14.9 \%)$ & $11(11.1 \%)$ & $15(14.7 \%)$ & \\
\hline Have not increased & $155(43.7 \%)$ & $73(47.4 \%)$ & $33(33.3 \%)$ & $49(48.0 \%)$ & \\
\hline $\begin{array}{l}\text { Unknown } \\
\text { Compared to the lockdown phase, } \\
\text { Do you consider that inflammatory } \\
\text { pathology-related admissions have } \\
\text { increased: }\end{array}$ & $67(18.9 \%)$ & $20(13.0 \%)$ & $41(41.4 \%)$ & $6(5.9 \%)$ & $<0.001$ \\
\hline$>75 \%$ & $11(3.1 \%)$ & $8(5.2 \%)$ & $1(1.0 \%)$ & $2(2.0 \%)$ & \\
\hline $50-75 \%$ & $31(8.7 \%)$ & $15(9.7 \%)$ & $5(5.1 \%)$ & $11(10.8 \%)$ & \\
\hline $25-51 \%$ & $73(20.6 \%)$ & $33(21.4 \%)$ & $22(22.2 \%)$ & $18(17.6 \%)$ & \\
\hline$<25 \%$ & $41(11.5 \%)$ & $14(9.1 \%)$ & $9(9.1 \%)$ & $18(17.6 \%)$ & \\
\hline Have not increased & $150(42.3 \%)$ & $70(45.5 \%)$ & $28(28.3 \%)$ & $52(51.0 \%)$ & \\
\hline Unknown & $49(13.8 \%)$ & $14(9.1 \%)$ & $34(34.3 \%)$ & $1(1.0 \%)$ & \\
\hline $\begin{array}{l}\text { Have you had to use telehealth } \\
\text { resources with your patients? }\end{array}$ & & & & & $<0.001$ \\
\hline Yes & $195(54.9 \%)$ & $75(48.7 \%)$ & $21(21.2 \%)$ & $(58.8 \%)$ & \\
\hline No & $160(45.1 \%)$ & $79(51.3 \%)$ & $78(78.8 \%)$ & $(41.2 \%)$ & \\
\hline
\end{tabular}

disagreed that telemedicine services are sufficient for postoperative follow-up consults. Likewise, $63.1 \%(n=224)$ disagreed that digital services are an adequate platform for continuing surgical education (Figure 3).

\section{Perception about Impact on Personal Life}

When surveyed about changes in their personal life, $22.8 \%(n=81)$ of participants reported having been required to quarantine at their homes, with $14.9 \%(n=53)$ of respondents reportedly moving to other housing, in an effort to reduce the risk of transmission of COVID-19 to their families. Though this varied significantly across levels of training; more residents reported to have been put under quarantine (39\% vs. $17.5 \%$ vs. $14.1 \%$; $\mathrm{p}=<0.001$ ) or have moved from their homeplace ( $31.4 \%$ vs. $11.7 \%$ vs. $3.1 \%$; $p=<0.001$ ) compared to general surgeons and subspecialist surgeons, respectively.

When considering the economic impact on surgeons, $82.6 \%(n=209)$ of respondents reported to have experienced cuts in their income during the last 3 months, without difference be- 
tween general and subespecialist surgeons (79\% vs. $88 \%$; $p=0.1)$. Furthermore, $32.4 \%(n=82)$ and $20.6 \%(n=52)$ of surgeons reported this decrease to be between $25-50 \%$ and $51-75 \%$, respectively. Likewise, $88.2 \%(n=90)$ of the residents reported decreasing numbers of operative cases during the last 3 months, with $55.9 \%(n=57)$ considering the magnitude of reduction more than $50 \%$ (Table 4 ).

\section{Discussion}

As surging numbers of new COVID-19 cases are being reported around the world, there is still some debate regarding how strict new strategies should be to mitigate the spread of the virus, as many countries fear the profound economic con- sequences of complete lockdowns ${ }^{9}$. Pre-existing structural inequality, uneven access to health care, and limited safety nets explain the wide variation seen in responses across Latin American countries. In Colombia, strict restrictions were implemented early on while measures to release, optimize and expand existing installed capacity were undertaken; thus, lower incidence and mortality rates than other countries in the region were observed ${ }^{10}$. However, with a second wave we were not exempt from collateral effects on hospitals and, particularly, the surgical community. Here we present the perceptions from surgeons and residents on the impact the pandemic has had on their clinical practice and personal life.

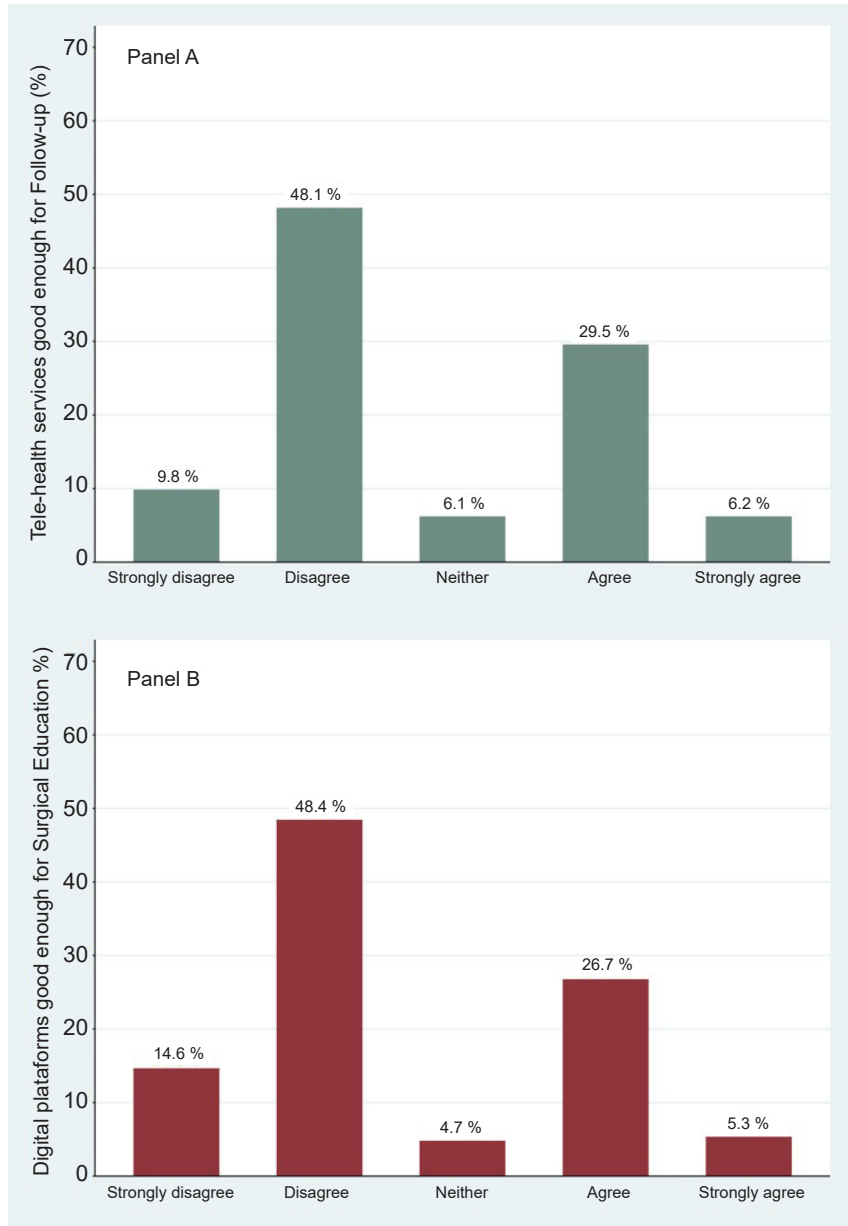

Figure 3. Perceptions about using digital platforms for surgical follow-up (Panel A) and surgical learning (Panel B). 
Table 4. Perception about personal life domain.

\begin{tabular}{|c|c|c|c|c|c|}
\hline Question & $\begin{array}{c}\text { Total } \\
(n=355)\end{array}$ & $\begin{array}{l}\text { General surgeon } \\
\quad(n=154)\end{array}$ & $\begin{array}{l}\text { Subspecialist } \\
\text { surgeon } \\
(n=99)\end{array}$ & $\begin{array}{l}\text { Resident } \\
(n=102)\end{array}$ & $p$ value \\
\hline $\begin{array}{l}\text { Have you had to moved to another housing } \\
\text { to avoid putting at risk your family? }\end{array}$ & & & & & $<0.001$ \\
\hline Yes & $53(14.9 \%)$ & $18(11.7 \%)$ & $3(3.0 \%)$ & $70(68.6 \%)$ & \\
\hline No & 302 (85.1\%) & $136(88.3 \%)$ & $96(97.0 \%)$ & $32(31.4 \%)$ & \\
\hline \multicolumn{6}{|l|}{$\begin{array}{l}\text { Have you had to use own resources to } \\
\text { adquire elements of personal protection? }\end{array}$} \\
\hline \multicolumn{6}{|l|}{ Yes } \\
\hline \multicolumn{6}{|l|}{ No } \\
\hline $\begin{array}{l}\text { Surgeons: Do you consider COVID-19 } \\
\text { has decreased your monthly income } \\
\text { during the last } 3 \text { months? }\end{array}$ & & & & & 0.93 \\
\hline Yes & $214(82.6 \%)$ & $125(78.6 \%)$ & $89(88.9 \%)$ & - & \\
\hline No & $39(17.4 \%)$ & $29(20.1 \%)$ & $10(10.1 \%)$ & - & \\
\hline $\begin{array}{l}\text { Surgeons: Do you consider your monthly } \\
\text { income during the last } 3 \text { months has } \\
\text { decreased: }\end{array}$ & & & & & 0.05 \\
\hline$>75 \%$ & $36(14.2 \%)$ & $16(10.4 \%)$ & $20(20.2 \%)$ & - & \\
\hline $51-75 \%$ & $52(20.6 \%)$ & $28(18.2 \%)$ & $24(24.2 \%)$ & - & \\
\hline $25-50 \%$ & $82(32.4 \%)$ & $52(33.8 \%)$ & $30(30.3 \%)$ & - & \\
\hline$<25 \%$ & $42(16.6 \%)$ & $26(16.9 \%)$ & $16(16.2 \%)$ & - & \\
\hline Has not decreased & $38(15.0 \%)$ & $30(19.5 \%)$ & $8(8.1 \%)$ & & \\
\hline \multicolumn{6}{|l|}{$\begin{array}{l}\text { Residents: Do you consider COVID-19 } \\
\text { pandemic has decreased the exposure } \\
\text { to surgical procedures during the last } 3 \\
\text { months? }\end{array}$} \\
\hline Yes & $90(88.2 \%)$ & - & - & $90(88.2 \%)$ & \\
\hline No & $12(11.8 \%)$ & - & - & $12(11.8 \%)$ & \\
\hline \multicolumn{6}{|l|}{$\begin{array}{l}\text { Residents: Do you consider the exposure } \\
\text { to surgical procedures during the last } 3 \\
\text { months has decreased: }\end{array}$} \\
\hline$>75 \%$ & $26(25.5 \%)$ & - & - & $26(25.5 \%)$ & \\
\hline $51-75 \%$ & $31(30.4 \%)$ & - & - & $31(30.4 \%)$ & \\
\hline $25-50 \%$ & $29(28.4 \%)$ & - & - & $29(28.4 \%)$ & \\
\hline$<25 \%$ & $7(6.9 \%)$ & - & - & $7(6.9 \%)$ & \\
\hline Has not decreased & $9(8.8 \%)$ & - & - & $9(8.8 \%)$ & \\
\hline
\end{tabular}

Compared to the survey conducted at the beginning of the pandemic, the second survey showed that surgeons and residents perceived better adherence to safety protocols at their institutions, in contrast to the $17 \%$ that considered those were completely met early in the pandemic.
Almost $60 \%$ reported recommendations are being fulfilled completely, with only $1.4 \%$ of respondents considering they are not being followed at all. Of the participants, residents were the subgroup that most often perceived room for improvement in this regard. Sufficient availability of PPE for 
residents is fundamental to mitigating the risk of COVID-19 transmission as cases continue to increase, as they were most likely to report direct contact with COVID-19 patients.

Although identifying institutional factors responsible for the lack of an absolute adherence to protocols is out of the scope of this survey, we did show that N95 masks and disposable gowns were the PPE most frequently reported to be out of stock. Delgado et al ${ }^{11}$ documented that only $56 \%$ of healthcare workers surveyed had access to N95 masks, being the second most frequently protective element lacking among respondents after face shields. Interestingy, only $4.8 \%$ participants identified lacking access to face shields in our data. Several factors may contribute to this finding: the disposable nature of PPE contributes to the shock of demand observed as both the general and healthcare population are using PPE; participants reported investing in more expensive PPE with their own economic resources, such as goggles or face shields. Finally, though the self-reported infection rate among respondents is low, we must emphasize the importance of ensuring PPE availability and its appropriate use among all surgical personnel.

One of the main objectives of conducting a follow-up survey was to describe the evolution in practice patterns as the pandemic progressed. Almost half of respondents reported a percieved increase in number of complications requiring treatment secondary to COVID-19 infection. This finding is not suprising given the increasing number of infected people combined with suboptimal diagnostic tests to detect the disease during the asymptomatic period ${ }^{12}$. The CovidSurg collaborative study found that postoperative pulmonary complications occur in half of the patients with perioperative SARS-CoV-2 infection and a two-fold increased 30-day mortality for those older than 70 years, in a sample of 1,128 patients who had both emergency surgery (74\%) and elective surgery $(42.8 \%)$ between January and March ${ }^{13}$.

Secondly, the vast majority of participants perceived that complications secondary to delayed ER consultations have also increased since the beginning of the pandemic. This is a recurrent pattern being reported by different medical specialties ${ }^{14,15}$. In a comparitive analysis of a retrospective cohort from 2019 and a cohort from 2020, O'Brien et at ${ }^{16}$ found that of patients presenting with acute abominal pain, there are increased rate of positive computed tomographic findings (32\% vs. $50 \%)$, increased rates of signs of complicated pathology (7.9\% to $19.7 \%$ ), and increased rate of patients requiring surgical intervention ( $26.3 \%$ vs $47.6 \%)$. These data highlight one of the biggest challenges we have had, balancing resources to continue providing care to non-COVID patients, as our services find a way to respond to the increased load of COVID-19 patients. The utilization of decision tools such as the MeNTS surgery scoring system ${ }^{17}$ have proved to be useful in prioritizing patients when nonoperative options are not available, or are less effective, to reduce the amount of unnecessary services used. However, it is the responsibility of the healthcare system to proactively inform the general population about the importance of timely consultation to the ER whenever is neccesary.

Telemedicine platforms are a powerful tool to address the fear of exposure to COVID, triaging the general population with acute or chronic disease, and optimizing health services delivery. Although half of the general surgeons and almost $80 \%$ of subspecialist surgeons reported having used telemedicine platforms during the pandemic, $58 \%$ of the respondents did not view telemedicine as sufficient for follow-up consults. Despite the nuances in follow-up for patients with major procedures, telemedicine applications have proven to be an efficient way to communicate with patients. A systematic review by Asiri et al ${ }^{18}$ including 24 studies from different surgical specialties, found that mobile phone-assisted applications improved postoperative follow-up and decreased the need for patients to attend ambulatory care for routine wound checks, as well as enabled strong connectivity between patients and the healthcare provider. Telemedicine is one example of how the pandemic has worked as a catalyst for finding new ways to care for patients. Telemedicine help 
patients adhere to social distancing policies, while optimize post-operative follow-up using video calls, or with a combination of phone calls and wound images taken and sent by patients.

Another issue the pandemic has made visible is the health workforce instability in Colombia. While $65 \%$ of the graduated participants working in more than 1 hospital might have foreseen the pandemic to have had a lesser impact on surgeons' financial side, more than $80 \%$ of surveyed surgeons reported a reduction in their monthly income. We can argue that the type of employment contract surgical providers have in our country is highly associated with the reduced incomes secondary to the cancelation of elective procedures. In a previous study led by the Colombian Surgical Association in 2009, $46 \%$ and $44 \%$ of the active and inactive members surveyed reported working through a fee for service contract ${ }^{19}$, a reality that can be higher given the number of new academic programs opened over the last 11 years. Second, given the low provider density in surgical services we have in Colombia ${ }^{4}$, it is expected that a significant proportion of this workforce is an itinerant healthcare network providing services to different regions in the country. It is easy to imagine that the reduced mobility during lockdowns and quarantined time decreases the possibility to provide surgical services. We can hypothesize then that the pandemic's impact will put more pressure on our system even when cases start falling given the complex relationship of backlogs patients, personnel shortage in an already saturated workforce, and delayed provision of surgical services to sicker patients.

The significant physical and emotional toll of the COVID-19 pandemic on healthcare workers has been well-documented ${ }^{20}$. More than $30 \%$ of residents reported moving out of their household to reduce the risk of transmission to their families. In addition to the personal impact of the pandemic on resident quality of life, the lanscape of surgical training has been significantly altered during the pandemic. By the time the survery was available, $88 \%$ of the residents who responded have reported a reduction in their exposure to surgical hands-on training opportunities. With the effects of the pandemic expected to last for many more months, the education division from the Colombian Surgical Association released some recommendations to help mitigate the impact of the pandemic on surgical resident training ${ }^{21}$. For example, surgical simulation may provide a valuable alternative to residents for practicing their surgical skills in combination with workshops of recorded surgical procedures explained by the attending surgeons. In the end, it is a civil and moral obligation to continue to innovate and adapt in the face of the COVID-19 pandemic to optimize surgical training so that the quality of future surgeons is not undermined. Likewise, it is the academic programs' best interests to provide the material and financial resources needed to address the wellbeing and training of their surgical residents.

\section{Limitations}

This study has many inherent limitations due to the nature of a survey. Although it was distributed throgugh differents means, there was a responder bias given the high proportion of participants from the main cities. Furthermore, this study reflects opinions from academic institutions principally regarding the current challenges they are facing, which might not represent the reality other cities and institutions are facing. Also, as this study relies on self-reported data, there may be variability and inconsistency in the responses.

\section{Conclusion}

The second survey showed that surgeons and residents perceived better adherence to safety protocols at their institutions than at the beginning of the pandemic. However, the toll on economic and academic domains are substantial among the surgical community. As the effects of the pandemic are expected to last longer in our region, telemedicine services acceptance and healthcare providers' job stability need to be improved in Colombia. 


\section{Acknowledgments}

We would like to thank the Colombian Surgery Association for the support at delivering the survey to their members.

\section{Compliance with ethical standards}

This study does not entail ethical problems given the confidentiality of the information is ensured; the survey was voluntary, data is anonymous, and confidential information of patients or institutions is not available, therefore Institutional Review Board revision was waived.

\section{Disclosures}

The authors have no disclosures to report.

\section{Funding}

The authors received no financial support for the research, authorship, and/or publication of this article.

\section{Authors Contributions}

All authors contributed to the survey desing, data analysis and manuscript elaboration.

\section{References}

1. Sen-Crowe B, McKenney M, Elkbuli A. Social distancing during the COVID-19 pandemic: Staying home save lives. Am J Emerg Med. 2020;38:1519-20. https://doi.org/10.1016/j.ajem.2020.03.063

2. Lu FS, Nguyen AT, Link N, Santillana M. Estimating the prevalence of COVID-19 in the United States: Three complementary approaches. medRxiv. 2020 Jan 1. https://doi.org/10.1101/2020.04.18.20070821

3. Litewka SG, Heitman E. Latin American healthcare systems in times of pandemic. Dev World Bioeth. 2020;20:69-73. https://doi.org/10.1111/dewb.12262

4. Hanna JS, Herrera-Almario GE, Pinilla-Roncancio M, Tulloch D, Valencia SA, Sabatino ME, et al. Use of the six core surgical indicators from the Lancet Commission on Global Surgery in Colombia: a situational analysis. Lancet Glob Heal. 2020;8:e699-710. https://doi.org/10.1016/S2214-109X(20)30090-5

5. Meara JG, Leather AJM, Hagander L, Alkire BC, Alonso N, Ameh EA, et al. Global Surgery 2030: evidence and solutions for achieving health, welfare, and economic development. Lancet. 2015;386:569-624. https://doi.org/10.1016/S0140-6736(15)60160-X

6. Cuevas-López L, Ayala Acosta JC, Velásquez-Jiménez OA, Navarro-Alean4 JA, González-Higuera LG, Zurita Medrano N, et al. Recomendaciones para el manejo de los pacientes quirúrgicos urgentes durante la pandemia covid-19. Rev Colomb Cirugía. 2020;35:143-52. https://doi.org/10.30944/20117582.619
7. The Lancet. COVID-19 in Latin America: a humanitarian crisis. Lancet. 2020;396:1463. https://doi.org/10.1016/S0140-6736(20)32328-X

8. DIaz-Castrillon C, Cortes M, Rey S, Pineda M, Diaz-Castrillon J, Sierra S. Percepción de la pandemia COVID-19 en los servicios de cirugía en Colombia. Rev Colomb Cirugía. 2020;35:290-301. https://doi.org/10.30944/20117582.655

9. Nicola M, Alsafi Z, Sohrabi C, Kerwan A, Al-Jabir A, Iosifidis $\mathrm{C}$, et al. The socio-economic implications of the coronavirus pandemic (COVID-19): A review. Int J Surg. 2020;78:185-93. https://doi.org/10.1016/j.ijsu.2020.04.018

10. De la Hoz-Restrepo F, Alvis-Zakzuk NJ, De la Hoz-Gomez JF, De la Hoz A, Gómez Del Corral L, Alvis-Guzmán N. Is Colombia an example of successful containment of the 2020 COVID-19 pandemic? A critical analysis of the epidemiological data, March to July 2020. Int J Infect Dis. 2020;99:522-9. https://doi.org/10.1016/j.ijid.2020.08.017

11. Delgado D, Wyss Quintana F, Perez G, Sosa Liprandi A, Ponte-Negretti C, Mendoza I, et al. Personal safety during the COVID-19 pandemic: Realities and perspectives of healthcare workers in Latin America. Int J Environ Res Public Health. 2020;17:2798. https://doi.org/10.3390/ijerph17082798

12. Díaz-Castrillón CE. La incertidumbre en la apertura de los servicios de cirugía ambulatoria en Colombia. Rev Colomb Cirugía. 2020;35:526-8. https://doi.org/10.30944/20117582.732

13. Nepogodiev D, Bhangu A, Glasbey JC, Li E, Omar OM, Simoes JF, et al. Mortality and pulmonary complications in patients undergoing surgery with perioperative SARS-CoV-2 infection: an international cohort study. Lancet. 2020;396:27-38. https://doi.org/10.1016/S0140-6736(20)31182-X

14. Shah K, Tang D, Ibrahim F, Ghosh B, Bhatti S, Akhabue $\mathrm{E}$, et al. Surge in delayed myocardial infarction presentations. JACC Case Reports. 2020;2:1642-7. https://doi.org/10.1016/j.jaccas.2020.07.004

15. Schirmer CM, Ringer AJ, Arthur AS, Binning MJ, Fox WC, James RF, et al. Delayed presentation of acute ischemic strokes during the COVID-19 crisis. J Neurointerv Surg. 2020;12:639-42. https://doi.org/10.1136/neurintsurg-2020-016299

16. O’Brien CM, Jung K, Dang W, Jang H-J, Kielar AZ. Collateral damage: The impact of the COVID-19 pandemic on acute abdominal emergency presentations. J Am Coll Radiol. 2020;17:1443-9. https://doi.org/10.1016/j.jacr.2020.08.010

17. Prachand VN, Milner R, Angelos P, Posner MC, Fung JJ, Agrawal N, et al. Medically necessary, time-sensitive 
procedures: scoring system to ethically and efficiently manage resource scarcity and provider risk during the COVID-19 pandemic. J Am Coll Surg. 2020;231:281-8. https://doi.org/10.1016/j.jamcollsurg.2020.04.011

18. Asiri A, AlBishi S, AlMadani W, ElMetwally A, Househ M. The use of telemedicine in surgical care: A systematic review. Acta Inform Medica. 2018;26:201. https://doi.org/10.5455/aim.2018.26.201-206

19. Saul Rugeles. El ejercicio de la Cirugía en Colombia: una encuesta nacional y algunas reflexiones sobre sus resultados. Rev Colomb Cirugía. 2009;24:147-52.
20. Sierra-Tobon S, Diaz-Castrillon CE. Inteligencia emocional y práctica clínica en tiempos de pandemia. CES Med. 2020;Especial COVID-19:59-68.

http://dx.doi.org/10.21615/cesmedicina.34.COVID-19.9

21. Dominguez Torres LC, Torregrosa Almonacid L, Sánchez Maldonado W, Lasprilla N, Vargas Barato F, Niño Rodríguez ÁE, et al. Educación quirúrgica durante la Pandemia COVID-19: Primer consenso nacional de la División de Educación de la Asociación Colombiana de Cirugía. Rev Colomb Cirugía. 2020;35:363-72. https://doi.org/10.30944/20117582.739 